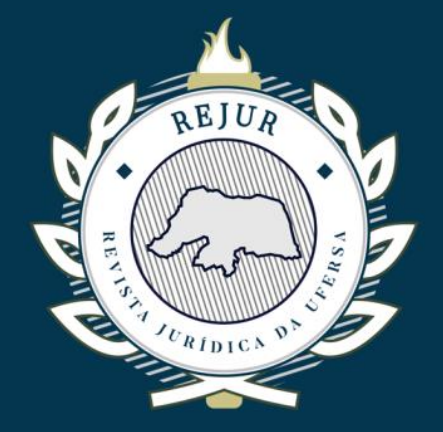

\title{
A CAPACIDADE CIVIL E A CURATELA PARA A PESSOA COM DEFICIÊNCIA MENTAL APÓS A LEI No $13.146 / 2015$
}

THE CIVIL CAPACITY AND THE TRUSTEESHIP FOR PEOPLE WITH MENTAL DESABILITIES AFTER LAW № 13.146/2015

\author{
Carina Baia Rodrigues* | Nicolau Eládio Bassalo Crispino**
}

\section{RESUMO}

O estudo objetiva expor as diferenças entre a curatela apresentada no Código Civil de 2002, em sua redação original, e a curatela exposta pela Lei no 13.146/2015, Estatuto da Pessoa com Deficiência. Aborda a capacidade civil das pessoas com deficiência no decorrer dos Códigos Civis brasileiros, bem como o tratamento despendido a tais sujeitos na codificação. Informa sobre a origem do Estatuto da Pessoa com Deficiência, revelando parte do entendimento doutrinário sobre a curatela e a capacidade civil nos moldes em que eram tratados antes da Lei no 13.146/2015. Expõe a Tomada de Decisão Apoiada, inovação do sistema protetivo. Utilizou-se o método Dialético, com procedimentos secundários Histórico e Comparativo, posto que se buscou a gênese do instituto da curatela no ordenamento brasileiro para, posteriormente, realizar o confronto entre o modelo anteriormente estabelecido com aquele vigente a partir de 2016. Por fim, se chegou à conclusão de que a curatela, em seus novos contornos, bem como a Tomada de Decisão Apoiada, proporciona para a pessoa com deficiência mental maior autonomia bem como the promove a efetividade do princípio da dignidade da pessoa humana.

Palavras-chave: Lei no 13.146/2015. Estatuto da Pessoa com Deficiência. Curatela. Capacidade Civil.

\section{ABSTRACT}

This study aims to expose the differences between trusteeship as presented in the original version of the Brazilian Civil Code of 2002, and trusteeship according to Brazilian Law for the Inclusion of People with Disabilities (Law 13,146 of 2015). It also addresses the civil capacity of people with disabilities as well as the treatment applied to such subjects by different Brazilian Civil Codes throughout history. It reports on the origins of the Statute of the People with Disabilities, revealing part of the doctrinal understanding of trusteeship and civil capacity prior to Law 13.146/2015. It exposes supported decisionmaking as innovation of the protective system. The Dialectic method was used, with historical and comparative methods as secondary procedures, since the genesis of the institute of trusteeship in Brazilian legal order was sough before the confrontation between the model previously established and the one valid since 2016 was carried out. Finally, we arrived to the conclusion that the trusteeship, in its new contours, along with supported decision-making, provides greater autonomy for people with disabilities and promotes the effectiveness of the dignity of the human person principle

Keywords: Law 13.146/2015. Statute of the People with Disabilities. Trusteeship. Civil Capacity.

\footnotetext{
* Mestranda do Programa de Pós-graduação em Educação da Universidade Federal do Amapá. Auditora de
} Controle Externo do Tribunal de Contas do Estado do Amapá.

carengaby@hotmail.com

** Doutor em Direito Civil pela USP. Professor do Curso de Graduação em Direito e do Mestrado em Direito

Ambiental e Políticas Públicas da UNIFAP. Procurador de Justiça do Ministério Público do Estado do Amapá.

Membro do Instituto de Direito Comparado Luso-Brasileiro. Diretor do IBDFAM no Estado do Amapá. nicolaucrispino@gmail.com 


\section{SUMÁRIO}

INTRODUÇÃO; 1 A PESSOA COM DEFICIÊNCIA MENTAL NA PERSPECTIVA CIVIL BRASILEIRA; 1.1 Da deficiência mental; 1.2 Da capacidade civil e da curatela para a pessoa com deficiência mental;

2 ORIGEM DO ESTATUTO DA PESSOA COM DEFICIÊNCIA; 2.1 Alteração no paradigma da capacidade civil; 3 CRÍTICAS AO NOVO MODELO DE INCAPACIDADES ADOTADO PELA LEI № 13.146/2015; CONCLUSÃO; REFERÊNCIAS.

\section{- INTRODUÇÃO}

Na codificação civil brasileira a capacidade das pessoas com deficiência mental foi abordada de diversas maneiras de acordo com o contexto social do período em que se encontrava inserida. No Código Civil de 1916, por exemplo, estas pessoas eram denominadas de loucos de todo o gênero e consideradas absolutamente incapazes. O Código Civil de 2002, por seu turno, ao tratar da capacidade civil das pessoas naturais, classificava aquelas com deficiência mental em absolutamente ou relativamente incapazes, conforme seu grau de discernimento para a prática de atos da vida civil.

A imposição da incapacidade a determinadas pessoas era entendida como uma maneira de o Estado promover a proteção daqueles considerados vulneráveis dentro do ordenamento, consistindo, então, em um dever social estatal. Nesse sentido, as pessoas com deficiência mental foram por muito tempo consideradas incapazes em virtude da força da lei bem como do senso comum, contido no Direito Civil, de que estas não possuíam habilidades mentais capazes de lhes proporcionar segurança para a realização de seus atos civis.

Para as pessoas com deficiência mental, declaradas como incapazes recaía, então, a curatela que, segundo os ensinamentos de Abreu e Val" ${ }^{1}$, "consiste no encargo conferido a uma pessoa para que, em conformidade com os limites jurídicos, cuide da pessoa declarada incapaz".

Gagliano e Pamplona Filho² afirmam que a curatela, em sua figura básica, visa a proteger a pessoas maior, padecente de alguma incapacidade ou de certa circunstância que impeça a sua livre e consciente manifestação de vontade, resguardando-se, com isso, também o seu patrimônio. Nesse sentido, o curador deteria a atribuição de administrar seguramente os bens do incapaz, podendo inclusive substituir a sua vontade sempre que necessário a fim de resguardar o seu patrimônio.

Essa desconsideração da vontade da pessoa com deficiência, acrescida da restrição imposta quanto à gestão de seu patrimônio, acabava por invadir a sua própria personalidade, vez que interferia na autonomia existencial do indivíduo, o que produzia, por consequência, uma diminuição deste na esfera social. Diante disso, percebe-se que o Estado não conseguia

\footnotetext{
${ }_{1}^{1}$ ABREU, Célia Barbosa; VAL, Eduardo Manuel. A flexibilização da curatela para o psicopata: uma interpretação constitucional pelo Superior Tribunal de Justiça. Rio Grande do Sul: Ajuris, 2014. p. 111.

${ }^{2}$ GAGLIANO, Pablo Stolze; PAMPLONA FILHO, Rodolfo. Manual de Direito Civil. São Paulo: Saraiva Educação, 2018.
} 
promover para as pessoas com deficiência mental a dignidade da pessoa humana em toda sua amplitude, ferindo assim um princípio fundamental da República Federativa do Brasil.

Não obstante ao quadro apresentado, as discussões das Nações Unidas sobre o tratamento empenhado para as pessoas com deficiência progrediram significativamente de modo a direcionar os países na promoção da dignidade da pessoa humana e da igualdade de oportunidades para esse grupo de pessoas, visando assim a eliminação da discriminação em todas as suas formas.

A Convenção Sobre os Direitos das Pessoas com Deficiência e o seu Protocolo Facultativo foram assinados em Nova lorque, em 30 de março de 2007, sendo que o Brasil ratificou tal Convenção por meio do Decreto n 6.949 , de 2009, que desencadeou a edição do Estatuto da Pessoa com Deficiência.

O Estatuto da Pessoa com Deficiência foi instituído pela Lei no 13.146/2015, a qual trouxe ao ordenamento brasileiro significativas mudanças sobre o assunto, de maneira que o Código Civil de 2002 deixou de considerar os portadores de deficiência mental relativa ou absolutamente incapazes para considerá-los absolutamente capazes.

O presente estudo aborda aspectos relevantes quanto à evolução da capacidade civil e da consideração da vontade da pessoa com deficiência ao longo da legislação brasileira, buscando demonstrar que as alterações implementadas pela Lei $n$ o 13.146/2015 concederamIhe maior autonomia como sujeito detentor de direitos, o que tende a the proporcionar igualdade de condições para com os demais nacionais, bem como a tão almejada dignidade da pessoa humana.

É, portanto, necessário o estudo aprofundado da Lei № 13.146/2015 para que haja reflexão da comunidade acadêmica acerca da temática e, ainda, o conhecimento da adaptação quanto às figuras que surgem com o referido diploma legal, tais como a Tomada de Decisão Apoiada e a Curatela Especial para aqueles que a lei passou a classificar como absolutamente capazes.

\section{A PESSOA COM DEFICIÊNCIA MENTAL NA PERSPECTIVA CIVIL BRASILEIRA}

O Brasil, no período que antecedeu a sua codificação civil, utilizou-se das Ordenações de Portugal como documentos de referência para tratar de tal matéria. Nas ordenações Afonsinas, vigentes até o ano de 1521, havia disposição no Livro IV, Título LXXXVI, de que os desassisados e pródigos deveriam receber curadores. O título revelava que se a justiça soubesse de que um sandeu, por causa de sua sandice, pudesse fazer mal ou dano à pessoa ou à fazenda deveria ser entregue ao seu pai, que seria seu curador, respondendo o pai pelos danos que o sandeu causasse. Nessa perspectiva, as pessoas com deficiência eram, portanto, consideradas incapazes e estavam sujeitas à curatela.

Nas Ordenações Manuelinas, que vigoraram de 1521 a 1603, o Livro IV tratava dos direitos civis e não existia detalhamento sobre a tutoria ou curadoria para aqueles que fossem considerados pródigos ou desassisados. Embora, previsse em seu Livro I, Título LXIX, que havia a figura do curador destinado ao amparo dos bens do ausente cativo em terras inimigas.

Finalmente, nas Ordenações Filipinas, que vigoraram por maior tempo no Brasil (de 1603 até a substituição gradativa de seus livros por normas específicas), no Livro IV, Título CII, 
havia a previsão de curadoria para os pródigos e mentecaptos. Esse título se assemelhava com o antes exposto nas Ordenações Afonsinas, uma vez que determinava que se o juiz soubesse de que algum sandeu pudesse provocar danos à pessoa ou à propriedade deveria entregá-lo ao cuidado de seu pai, que exerceria boa guarda sobre ele e, segundo o referido texto, os bens do sandeu eram entregues ao seu pai que o manteria dali em diante.

Destaca-se que as Ordenações Filipinas colocavam a pessoa com deficiência mental em um mesmo nível de tratamento que os animais, vez que determinava, em seu art. 66, 3, do Livro I, que o poder de polícia deveria ser utilizado para conter o perigo proveniente da divagação dos loucos e dos animais ferozes.

Como se pôde observar, nas ordenações mencionadas, a pessoa com deficiência mental era tratada de forma pejorativa e discriminatória, sendo, designada como louco, desassisado e sandeu. Segundo Requião, ${ }^{3}$ isso se dava em virtude do momento em que se encontrava a medicina, considerando-se, por exemplo, que a psicofarmacologia, que propiciou tratamento a diversos sujeitos que antes estariam renegados à segregação, só começa a se desenvolver no início da década de 1950.

O Código Civil de 1916 também fez referência às pessoas portadoras de transtorno mental. Nesse diploma, se registrou novamente a presença da carga pejorativa atribuída a tais sujeitos, especificamente quando se referia a estes como loucos de todo o gênero. Segundo o mencionado código, eles eram absolutamente incapazes, inadmissíveis como testemunhas, incapazes de testar e estavam sujeitos à curatela.

O Código Civil de 2002 apresentou significativo avanço, quanto aos termos empregados no trato das pessoas com deficiência mental, ao utilizar de expressões como enfermidade ou doença mental para se referir às particularidades de tais pessoas. Nota-se, evolução não apenas nos termos apresentados, mas também na maneira com que o sujeito passa a ser percebido no ordenamento jurídico, posto que a codificação trazia a possibilidade de reconhecimento da capacidade relativa de acordo com o grau de discernimento do indivíduo. Como bem acentua Maria Berenice Dias:

\begin{abstract}
Muitas vezes a mudança de palavras tem importante significado na construção de novos conceitos. Tal aconteceu com a forma de identificar um deficiente. Em um primeiro tempo chegou-se a chamá-los de "loucos de todo o gênero". Depois passaram a ser nominados de "portadores de necessidades especiais", ou "portadores de deficiências". Atualmente a expressão considerada politicamente correta é: pessoas com deficiência 4 .
\end{abstract}

Apesar das importantes mudanças trazidas no Código Civil de 2002, a sua redação original ainda restringia significativamente o plano da autonomia da pessoa com deficiência mental, ao dispor, por exemplo, em seu art. 228, II, que não poderiam ser aceitos como testemunhas os que, por enfermidade ou retardamento mental, não tivessem discernimento para a prática de atos civis, ou ainda, em seu art. 1.548, I, que declarava nulo o casamento contraído pelo enfermo mental.

\footnotetext{
${ }^{3}$ REQUIÃO, Maurício. Estatuto da Pessoa com Deficiência: Incapacidades e Interdição. Juspodivm: Bahia. 2016.

${ }^{4}$ DIAS, Maria Berenice. Manual de direito das famílias. 10. ed. rev., atual. e ampl. São Paulo: Editora Revista dos Tribunais, 2015.p. 681.
} 


\subsection{Da deficiência mental}

Apesar de a legislação ter tutelado em diversos momentos os interesses dos deficientes mentais, não se aprofundou ao descrever no que consistia a deficiência ou enfermidade mental, até mesmo porque diante de casos concretos cabe à perícia médica determinar o tipo de enfermidade mental e sua amplitude. De maneira que tais conceitos advêm da medicina e de seus desdobramentos, como a psiquiatria e a psicopatologia, e, muito embora influenciem na definição de determinadas situações jurídicas, são conceitos externos ao direito e à própria codificação civil, conforme assevera Requião:

Utiliza-se o termo transtorno mental para se referir à existência de uma doença ou síndrome que de alguma maneira faça com que o sujeito possua padrão psíquico que se afaste daquele considerado normal. É uma categoria que encontra suas bases na medicina, mais especificamente na psiquiatria e psicopatologia 5 .

Além da evidente influência da área da saúde, não se pode desconsiderar que incidem fatores sociais na construção do que se entende por transtorno mental. Por muito, preocupou-se em estipular um padrão social de normalidade quanto ao intelecto humano, os padrões, porém, sempre foram determinados pela visão do homem sobre o próprio homem, tratando-se, de uma construção ontológica, segundo a qual o ser humano é aquele dotado de razão, sendo que a ausência ou deficiência de razão seriam ensejadores de uma classificação da pessoa como um ser anormal.

Os critérios de normalidade e anormalidade, mais do que simplesmente consequências de fatores biológicos e químicos, o são com base em análise humana realizada sobre os mesmos. Assim é que a definição de regulamentação do patológico depende também de fatores culturais e transdisciplinares, passando por conhecimentos da área da medicina, da psicologia e do direito, sem que se pretenda estar realizando rol taxativo ${ }^{6}$.

Na tentativa de uma aproximação da definição legal do termo, destaca-se a Lei no 13.146/2015, o Estatuto da Pessoa com Deficiência, a qual considera em seu artigo 2º, que a pessoa com deficiência é aquela que tem o impedimento de longo prazo de natureza física, mental, intelectual ou sensorial, o qual, em interação com uma ou mais barreiras, pode obstruir sua participação plena e efetiva na sociedade em igualdade de condições com as demais pessoas.

Em um sentido mais específico, prevê o Decreto Legislativo no 5.296/2004, em seu art. 5o, alínea d, que a deficiência mental consiste no funcionamento intelectual

\footnotetext{
${ }^{5}$ REQUIÃO, Maurício. Estatuto da Pessoa com Deficiência: Incapacidades e Interdição. Juspodivm: Bahia. 2016. p. 150.

${ }^{6}$ REQUIÃO, Maurício. Estatuto da Pessoa com Deficiência: Incapacidades e Interdição. Juspodivm: Bahia. 2016.p. 83.
} 
significativamente inferior à média, com manifestação antes dos dezoito anos e limitações associadas a duas ou mais áreas de habilidades adaptativas, tais como: comunicação; cuidado pessoal; habilidades sociais; utilização dos recursos da comunidade; saúde e segurança; habilidades acadêmicas; lazer e trabalho.

Pode-se então verificar que existe uma multiplicidade de conceitos, nas mais variadas áreas de conhecimento no que se refere às doenças mentais, não sendo objeto do presente estudo esgotar as significações do termo, de sorte que se utilizarão aqui genericamente as expressões pessoa com deficiência mental ou pessoa com transtorno mental para se referir aos sujeitos estudados.

\subsection{Da capacidade civil e da curatela para a pessoa com deficiência mental}

O Código Civil de 1916 criou um sistema de incapacidades fundamentado na proteção dos interesses patrimoniais do incapaz. A codificação baseava-se, portanto, na ideia de que o incapaz era um ser vulnerável e, consequentemente, merecedor de proteção específica. Assim, o art. 5o, II, do código de 1916 estabelecia que eram absolutamente incapazes de exercer pessoalmente os atos da vida civil os loucos de todo o gênero.

Quanto a esse Código, destaca-se o que se entendeu por redução da autonomia das pessoas com transtorno mental, haja vista que não se reconheceram os intervalos lúcidos do sujeito como previsto nas Ordenações Filipinas, nas quais as ações do louco sobre seu patrimônio eram válidas, desde que ocorresse em seus intervalos de lucidez.

O Código Civil de 2002, por sua vez, não considerou os intervalos lúcidos e no que se refere à capacidade dotou de personalidade jurídica toda pessoa nascida com vida, o que implica dizer que tais pessoas são capazes em direitos e obrigações. Gagliano e Pamplona Filho ${ }^{7}$ lecionam que a essa capacidade adquirida com advento do nascimento dá-se o nome de capacidade de direito ou de gozo e é comum a todos os seres humanos pelo fato de que a personalidade jurídica é um atributo inerente a sua condição.

Entretanto, essa capacidade genérica concedida a todos pelo ordenamento não autoriza o sujeito a atuar sozinho em sua vida civil, tendo em vista que se cuidou legalmente em balizar a prática de determinados atos por aqueles que possuem limitações de natureza orgânica ou psicológica que em tese impossibilitariam a pessoa de opinar sobre a administração de seu patrimônio.

Para Gagliano e Pamplona Filho, ${ }^{8}$ quando a pessoa é capaz de atuar pessoalmente em seus atos, ou seja, quando possui aptidão para exercer pessoalmente os seus direitos diz-se que ela possui a capacidade civil de fato ou de exercício. Os autores completam afirmando que, se o sujeito possui a capacidade civil de direito acrescida à de fato ou de exercício, este possui então a capacidade civil plena. Em contrapartida, é importante que se trate da incapacidade absoluta, termo utilizado na codificação civil de 2002 , que consiste na falta de aptidão para a prática de atos da vida civil, o absolutamente incapaz não possui, então, a capacidade de fato.

\footnotetext{
7 GAGLIANO, Pablo Stolze; PAMPLONA FILHO, Rodolfo. Manual de Direito Civil. São Paulo: Saraiva, 2018.

${ }^{8}$ GAGLIANO, Pablo Stolze; PAMPLONA FILHO, Rodolfo. Manual de Direito Civil. São Paulo: Saraiva, 2018.
} 
Extrai-se do Código Civil de 2002 que a pessoa ao completar os dezoito anos de idade adquire a capacidade civil plena, no entanto, o próprio código limitou o pleno exercício da capacidade a determinadas pessoas, as quais foram julgadas incapazes de cuidar de seus próprios interesses.

Compunha o rol dos absolutamente incapazes, na redação inicial do Código de 2002, os que por enfermidade ou deficiência mental, não tivessem o necessário discernimento para a prática de atos. Nessa perspectiva, os absolutamente incapazes não possuem capacidade de agir, sendo irrelevante, do ponto de vista jurídico o seu querer. Para que possam usufruir da capacidade de direito de que dispõem, devem agir representados por terceira pessoa. De sorte que o querer do representante determinará se o representado realizará ou não determinado ato jurídico.

A incapacidade impediria então que o sujeito realizasse o que se resguarda aos que possuem a capacidade civil de fato, como a prática de ato-fato jurídico, a manifestação de vontade por meio da realização de negócios jurídicos, aptidão para tornar-se empresário, além de diversos atos já apontados como: casar, testar, testemunhar, entre outros.

Não se pode negar que o Código Civil de 2002 representou significativo avanço no paradigma implementado ao determinar que a pessoa com deficiência mental seria considerada absoluta ou relativamente incapaz, a depender do seu grau de discernimento. Nota-se, com o reconhecimento parcial da autonomia apresentado, que tais pessoas iniciam um processo de validação da sua vontade. Como bem acentua Requião ${ }^{9} .:$ "Esta mudança, decerto, pode ser apontada como um avanço na regulação da limitação da autonomia, já que passou a guardar a autonomia do incapaz por distúrbios mentias, possibilitando-lhes, ao menos, alcançar a incapacidade relativa".

Para as pessoas com deficiência mental, o Código de 2002 reservou a possibilidade de sujeição à curatela, conforme se verifica na redação do art. 1.767 , antes da alteração promovida pela Lei no 13.146/2015:

Art. 1.767. Estão sujeitos a curatela:

I - aqueles que, por enfermidade ou deficiência mental, não tiverem o necessário discernimento para os atos da vida civil;

II - aqueles que, por outra causa duradoura, não puderem exprimir a sua vontade;

III - os deficientes mentais, os ébrios habituais e os viciados em tóxicos;

IV - os excepcionais sem completo desenvolvimento mental;

Nesse contexto, a curatela se apresentava como um instrumento protetivo e assistencial apto a conservar os interesses dos maiores de idade, os quais, por limitação legal foram declarados incapazes. É uma atribuição ordenada a alguém que se ache apto para zelar pelos interesses e patrimônio desse incapaz.

Entendia-se que o sujeito incapaz necessitava de alguém responsável pela suplementação de sua capacidade, vez que não possuía pleno discernimento. A curatela,

\footnotetext{
${ }^{9}$ REQUIÃO, Maurício. Estatuto da Pessoa com Deficiência: Incapacidades e Interdição. Juspodivm: Bahia. 2016. p.68.
} 
segundo Dias, ${ }^{10}$ tem caráter supletivo da capacidade. "Trata-se ainda de um múnus público: encargo conferido por lei a alguém, para reger a pessoa e administrar os bens de maiores que, por si mesmos, não possam fazê-lo".

A autora lembra, portanto, o interesse público presente no instituto, sendo a curatela um encargo imposto pelo Estado a alguém em prol de benefícios para a coletividade, assim, revela uma tendência legal de o Estado limitar o campo de atuação do sujeito, partindo do pressuposto de que as pessoas com deficiência mental não teriam habilidades suficientes para conduzir as suas vidas.

Apesar de a curatela se apresentar como instrumento protetivo destinado à administração patrimonial daqueles que não teriam (em tese) condições de fazê-lo, acabava por ferir a própria personalidade do sujeito, haja vista que as restrições introduzidas, ainda que apenas na regência dos bens, tocavam na autonomia existencial, de sorte que a curatela, como apresentada inicialmente na codificação civil tendia a tornar o interdito uma pessoa esvaziada de liberdade e de dignidade.

\begin{abstract}
A despeito disso, acredita-se aqui que outro sentido se pode dar à palavra autonomia retirando-a do contexto meramente patrimonialista, e transportando-a até a esfera identificada com as liberdades pessoais do sujeito. É nesse sentido que se fala aqui de autonomia existencial. A autonomia existencial, portanto, se identifica com a liberdade do sujeito em gerir a sua vida, sua personalidade, de forma digna ${ }^{11}$.
\end{abstract}

Como bem destaca o autor, a interferência estatal na autonomia do sujeito chegava ao ponto de influenciar na ausência de liberdade de forma que este não podia usufruir dignamente de sua vida e de sua própria personalidade. Desse modo, a doutrina debruçavase sobre o sistema de incapacidades sem o necessário aprofundamento dessas questões relacionadas ao direito de personalidade do incapaz, o qual com a interdição, via-se tolhido, por vezes, de sua própria existência.

Dias $^{12}$, antes mesmo da entrada em vigor da Lei no $13.146 / 2015$, já indicava a necessidade de se proporcionar a maior liberdade possível ao curatelado, de modo que a interdição não implicasse na supressão de autonomia e dos espaços de liberdade do sujeito, isso porque a autonomia da vontade está intimamente ligada ao livre desenvolvimento da personalidade.

As restrições à incapacidade de agir não existem para alhear os incapazes, mas para integrá-los ao mundo estritamente negocial. Segundo Pietro Perlingieri, é preciso privilegiar, sempre que possível, as escolhas da vida que o deficiente psíquico é capaz, concretamente, de exprimir, ou em relação às quais manifesta notável propensão. A disciplina da interdição não pode ser traduzida em uma incapacidade

\footnotetext{
${ }^{10}$ DIAS, Maria Berenice. Manual de direito das famílias. 10. ed. rev., atual. e ampl. São Paulo: Editora Revista dos Tribunais, 2015. p. 682.

${ }^{11}$ REQUIÃO, Maurício. Estatuto da Pessoa com Deficiência: Incapacidades e Interdição. Juspodivm: Bahia. 2016. p.31.

12 DIAS, Maria Berenice. Manual de direito das famílias. 10. ed. rev., atual. e ampl. São Paulo: Editora Revista dos Tribunais, 2015.
} 
legal absoluta, em uma "morte civil". Permitir que o curatelado possa decidir, sozinho, questões para as quais possui discernimento é uma forma de tutela da pessoa humana, pois a autonomia da vontade é essencial para o livre desenvolvimento da personalidade ${ }^{13}$.

Ficava evidenciado que os institutos protetivos para as pessoas com deficiência mental precisavam ser repensados, vez que a curatela, como instituída, se mostrava extremamente invasiva à personalidade do sujeito, o qual tinha, por vezes, o seu querer substituído pelas decisões de seu curador. Não há como se negar também a redução da dignidade da pessoa humana nessa relação, pois o incapaz, como já mencionado, acabava por se esvaziar de si mesmo no processo da interdição.

Integrada à ideia de amplitude do reconhecimento da vontade do interdito, Dias ${ }^{14}$ apresenta a possibilidade de gradação da curatela, pontuando que existem diversos graus de nível de consciência do interditado, de modo que o instituto deveria admitir gradações distintas de acordo com cada um deles.

Para a autora, a interdição absoluta é aquela que se procede no caso de ausência total de capacidade, posto que, caso o incapaz venha a praticar algum ato sozinho, a consequência jurídica é de nulidade, conforme preceitua o art. 166 do Código Civil. Por outro lado, a interdição deve ser limitada para os que possuem discernimento parcial, sendo que os atos praticados pelo parcialmente capaz não são necessariamente nulos, mas podem ensejar anulação.

Dias ${ }^{15}$ também sinalizava para a possibilidade de concessão de curatela compartilhada, ao dispor que, embora a previsão contida no Código Civil, art. 1.775 , §1으 conferisse legitimidade ao pai ou à mãe para o exercício da curatela, era necessário reconhecer a possibilidade de ambos os genitores exercerem de forma compartilhada tal tarefa, uma vez que não havia impedimentos para que exercessem o encargo em conjunto. Isso porque:

Situações particulares como a tutela de netos e a curatela de filhos não podem ficar atreladas à rigidez das normas nem prescindir da utilização de novos critérios hermenêuticos de afirmação, que cumprem a verdadeira finalidade do direito: garantir ao cidadão o exercício efetivo de seus direitos fundamentais ${ }^{16}$.

Como se pode observar, para que a curatela pudesse operar seus efeitos, era necessário o estabelecimento de um processo de interdição, por meio do qual a autoridade judiciária, após análise do caso concreto, determinava a substituição da vontade do curatelado pela do curador.

\footnotetext{
${ }^{13}$ DIAS, Maria Berenice. Manual de direito das famílias. 10. ed. rev., atual. e ampl. São Paulo: Editora Revista dos Tribunais, 2015. p. 688.

${ }^{14}$ DIAS, Maria Berenice. Manual de direito das famílias. 10. ed. rev., atual. e ampl. São Paulo: Editora Revista dos Tribunais, 2015.

${ }^{15}$ DIAS, Maria Berenice. Manual de direito das famílias. 10. ed. rev., atual. e ampl. São Paulo: Editora Revista dos Tribunais, 2015.

${ }^{16}$ DIAS, Maria Berenice. Manual de direito das famílias. 10. ed. rev., atual. e ampl. São Paulo: Editora Revista dos Tribunais, 2015. p.687.
} 
Destaca-se que a solicitação da interdição poderia ser feita mesmo sem representar a vontade da família do interdito, sendo possível, por exemplo, o início do procedimento por solicitação do representante do Ministério Público. Tanto que Dias em seus ensinamentos ressalta que:

Em qualquer caso de doença mental, mesmo não sendo considerada loucura furiosa, o representante do Ministério Público está legitimado a promover a interdição, se os parentes, cônjuge ou companheiro não o tiverem feito. O simples fato de existir pessoa sujeita à curatela, porém não ainda interditada, já autoriza o Ministério Público a agir, não sendo necessário que notifique antes as demais pessoas mencionadas no art. 1.768, estipulando-Ihes um prazo para suprir a omissão ${ }^{17}$.

A curatela deveria recair tão somente sobre o patrimônio do interdito, entretanto, a experiência brasileira demonstrou que a atuação do curador, por vezes, extrapolava a dimensão patrimonial. Os curadores da pessoa com deficiência, por exemplo, limitavam a liberdade de locomoção destes, tendiam a infantilizar a pessoa do interdito, negavam-lhe a possibilidade de envolvimento afetivo e desconsideravam a própria sexualidade do sujeito.

Até porque, ao tratar da possibilidade do portador de transtorno mental em ter relações sexuais, se termina, inevitavelmente retornando a problemas que estão no cerne da discussão sobre a sua autonomia, como a própria capacidade de consentimento e entendimento ${ }^{18}$.

Registra-se que o curador em um espírito paternalista, até mesmo porque pela regra do art. 1.775 e seus parágrafos do Código Civil, são o cônjuge, pais e descendentes que devem, prioritariamente, assumir esse encargo, tende a restringir o exercício de direitos por parte do interdito por entender que estes são desprovidos do preparo necessário para a prática desses atos. Conforme Requião:

Três são as atitudes normalmente adotadas diante do portador de deficiência: indiferença, caridade e paternalismo. Na indiferença, simplesmente se exclui o sujeito do convívio social [...]. Na caridade, muitas vezes haveria uma objetificação do deficiente, que é utilizado como meio para que possa o caridoso alcançar suas boas obras. Por fim, no paternalismo, embora a pessoa portadora de deficiência tenha direitos, não estaria preparada para exercê-los ${ }^{19}$.

Em verdade, o sistema de incapacidades para as pessoas com deficiência mental, como proposto pelo Código Civil de 2002, desconsiderou fortemente a vontade de tais pessoas sob o argumento de existir um dever social do Estado em preservar o patrimônio destas, o que

\footnotetext{
${ }^{17}$ GONÇALVES, Carlos Roberto, Direito de familia. 16. ed. - São Paulo: Saraiva, 2012. p. 406.

18 REQUIÃO, Maurício. Estatuto da Pessoa com Deficiência: Incapacidades e Interdição. Juspodivm: Bahia. 2016. p. 135.

${ }^{19}$ REQUIÃO, Maurício. Estatuto da Pessoa com Deficiência: Incapacidades e Interdição. Juspodivm: Bahia. $2016 .$. p.135
} 
justificaria, portanto, a substituição da vontade do incapaz pela de seu curador em uma receita rígida que não permitia espaços para manifestação dos anseios do curatelado.

A Lei no 13.146 , de 2015 , se insurge como um marco promotor da alteração desse sistema de incapacidades, de sorte que, a partir da entrada em vigor dessa lei no ordenamento jurídico, ineditamente, a vontade da pessoa com deficiência mental, antes considerada absolutamente incapaz, foi finalmente considerada na gerência de sua vida.

\section{ORIGEM DO ESTATUTO DA PESSOA COM DEFICIÊNCIA}

Em um obscuro período da história, as diferenças entre os seres humanos eram promovidas e destacadas como um motivo fundamental para a supressão de direitos e para a desconsideração de determinados grupos como detentores da dignidade humana, havia, portanto, um motivo legitimador do desprezo para com estes grupos. Piovesan ${ }^{20}$, destaca que, em situações limites, o homem foi considerado um ser esvaziado mesmo de qualquer dignidade, um ser descartável, um ser supérfluo.

Piovesan observa que as mais graves violações aos direitos humanos tiveram como fundamento a dicotomia do "eu versus o outro", em que a diversidade era captada como elemento para aniquilar direitos. Esse destaque e rejeição da diversidade, se vê perfeitamente demonstrado nos horrores vivenciados na Segunda Guerra Mundial, especialmente, pelos atos praticados na Alemanha nazista, momento no qual se evidenciou a necessidade de uma tutela internacional que reconhecesse o homem como sujeito de direitos independentemente de etnia, religião ou outro meio discriminatório.

A proteção dos sujeitos a cargo unicamente do Estado mostrou-se, portanto, insuficiente, de sorte que as nações revelaram ser indispensável um tratamento digno e igualitário a ser despendido a todo o ser humano indistintamente. Nessa perspectiva, Piovesan acentua que: "Fortalece-se a ideia de que a proteção dos direitos humanos não deve se reduzir ao domínio reservado do Estado, porque revela tema de legítimo interesse internacional".

Nesse sentido, a primeira fase internacional dos Direitos Humanos, marcada pela elaboração da Declaração Universal dos Direitos Humanos, de 1948, demonstrava o repúdio internacional pela promoção da diferenciação dos homens. Ao afirmar que todos os seres humanos nascem livres e iguais em dignidade e em direitos, a Declaração apresenta uma proteção geral, destinada ao homem em virtude de sua condição de pessoa, à qual seria a única necessária para o fazer titular de direitos.

Esta fase baseava-se, então, na igualdade formal entre os homens. Após a referida Declaração, surge no cenário internacional uma série de outros instrumentos de promoção e de proteção aos direitos, seguindo, de igual modo, a concepção de igualdade formal então apresentada.

Paralelamente, implementavam-se discussões sobre a necessidade da proteção específica de determinados grupos, diante da existência real de práticas discriminatórias que

${ }^{20}$ PIOVESAN, Flávia. in Novos Comentários à Convenção sobre os Direitos das Pessoas com Deficiência. Secretaria de Direitos Humanos da Presidência da República (SDH/PR)/Secretaria Nacional de Promoção dos Direitos da Pessoa com Deficiência (SNPD): Brasília, 2014. 
atingiam de forma desproporcional, principalmente, as minorias étnico-raciais e as mulheres. É a chamada segunda fase de proteção dos direitos humanos, baseada na igualdade material. Nela, se destacam a Convenção Sobre a Eliminação de Todas as Formas de Discriminação Racial, de 1965, a Convenção Sobre a Eliminação de Todas as Formas de Violência Contra a Mulher, de 1979, e a Convenção da ONU Sobre os Direitos da Pessoa com Deficiência, de 2006.

Enquanto o sistema protetivo da primeira fase dos direitos humanos centrava seus esforços no direito à igualdade, proibindo todas as formas de discriminação, a segunda fase reconheceu que era necessário o ajuste entre a não discriminação e as políticas compensatórias, com vistas a acelerar a efetividade da igualdade como processo. Nesse sentido, Piovesan afirma que "Para assegurar a igualdade não basta apenas proibir a discriminação, mediante legislação repressiva. São essenciais as estratégias promocionais capazes de estimular a inserção e inclusão dos grupos socialmente vulneráveis nos espaços sociais" 21 .

Especificamente, sobre o grupo das pessoas com deficiência mental, há de se destacar que estas enfrentaram, por um longo período, todo o tipo de prática discriminatória, como a perda de privacidade, de liberdade e de domínio sobre os seus próprios corpos, foram desconsideradas como sujeitos de direito, julgados indignos até mesmo do convívio com os demais.

Com vistas a promover a igualdade material para as pessoas com deficiência, a Convenção da ONU Sobre os Direitos da Pessoa com Deficiência, e o seu Protocolo Facultativo, assinados em 30 de março de 2007, reafirma os diversos valores e princípios já confessados na Declaração Universal dos Direitos Humanos, inovando ao reconhecer, em seu preâmbulo, que a discriminação contra qualquer pessoa, por motivo de deficiência, configura violação da dignidade e do valor inerentes ao ser humano e que existe a necessidade de promover e proteger os direitos humanos das pessoas com deficiência, inclusive daquelas que requerem um maior apoio.

O texto reflete ainda a preocupação das nações com o fato de que, não obstante os diversos instrumentos e compromissos assumidos por elas, as pessoas com deficiência continuam a enfrentar barreiras contra sua participação como membros iguais da sociedade e violações de seus direitos humanos em todas as partes do mundo, destacando-se a importância da cooperação internacional para melhorar as condições de vida das pessoas com deficiência.

Em âmbito nacional, o Congresso, por meio do Decreto Legislativo no 186, de 2008, aprovou o texto da Convenção Internacional Sobre os Direitos das Pessoas com Deficiência, observando o disposto no art. 5ㅇ, § 3으, da Constituição Federal de 1988, segundo o qual os tratados e convenções internacionais sobre direitos humanos que forem aprovados, em cada casa do Congresso Nacional, em dois turnos, por três quintos dos votos dos respectivos membros, serão equivalentes às emendas constitucionais.

No ano de 2009, o então presidente do Brasil promulgou a referida Convenção por meio do Decreto no 6.949. Destaque-se que por terem sido preenchidos os requisitos do art. 5o, § 3ㅇ da Constituição Federal, a Convenção Internacional sobre os Direitos das Pessoas com

\footnotetext{
${ }^{21}$ PIOVESAN, Flávia. in Novos Comentários à Convenção sobre os Direitos das Pessoas com Deficiência. Secretaria de Direitos Humanos da Presidência da República (SDH/PR)/Secretaria Nacional de Promoção dos Direitos da Pessoa com Deficiência (SNPD): Brasília, 2014. p. 17
} 
Deficiência figura atualmente no ordenamento Jurídico Brasileiro como texto formalmente constitucional.

Em 6 de julho de 2015, foi promulgada a Lei no 13.146, de 2015, que instituiu o Estatuto da Pessoa com Deficiência, a qual em seu art. 1으, concorda com os termos da Convenção Internacional sobre os Direitos da Pessoa com Deficiência, ao informar que a referida lei se destina a assegurar e a promover, em condições de igualdade, o exercício dos direitos e das liberdades fundamentais por pessoa com deficiência, visando a sua inclusão social e cidadania. Sobre o estatuto:

Em verdade, este importante Estatuto, pela amplitude do alcance de suas normas, traduz uma verdadeira conquista social. Trata-se, indiscutivelmente, de um sistema normativo inclusivo, que homenageia o princípio da dignidade da pessoa humana em diversos níveis ${ }^{22}$.

O citado sistema normativo inclusivo se vê demonstrado no longo de todo o estatuto, sendo que, na oportunidade, se destaca a confirmação do art. 4ํ de que toda a pessoa com deficiência tem direito à igualdade de oportunidades com as demais pessoas e que não sofrerá nenhuma espécie de discriminação, e o que dispõe o art. 60 de que a deficiência não afeta a capacidade civil da pessoa, inclusive para: casar, exercer direitos sexuais e reprodutivos, decidir o número de filhos a ter, conservar a sua fertilidade, exercer o direito à família e à convivência familiar, bem como de exercer o direito à guarda, à tutela, à curatela e à adoção em igualdade de oportunidades com as demais pessoas.

Diante do idealizado por meio do Estatuto da Pessoa com Deficiência, nasceu a necessidade de se alterar diversos dispositivos infraconstitucionais visando à compatibilização das normas então vigentes com a promoção a dignidade apresentada, sendo que uma das alterações mais marcantes foi a sofrida pelo Código Civil quanto à capacidade das pessoas e às disposições gerais sobre a curatela, as quais serão oportunamente tratadas no curso do presente estudo.

\subsection{Alteração no paradigma da capacidade civil}

A Lei no 13.146/2015 provocou significativa alteração no modelo então consolidado, ao deixar claro em seu art. 60 que a deficiência não afeta a plena capacidade civil da pessoa, inclusive para: casar-se e constituir união estável; exercer direitos sexuais e reprodutivos; exercer o direito de decidir sobre o número de filhos e de ter acesso a informações adequadas sobre reprodução e planejamento familiar; conservar sua fertilidade, sendo vedada a esterilização compulsória; exercer o direito à família e à convivência familiar e comunitária; e exercer o direito à guarda, à tutela, à curatela e à adoção, como adotante ou adotando, em igualdade de oportunidades com as demais pessoas.

Nesse sentido, já se registra um reconhecimento gradativo dos direitos então negados para as pessoas com deficiência mental, como o direito de constituir família e de ter o seu

${ }^{22}$ GAGLIANO, Pablo Stolze. O Estatuto da Pessoa com Deficiência e o sistema jurídico brasileiro de incapacidade civil. p.01. 
casamento reconhecido, conforme se extrai de notícia publicada pelo Instituto Brasileiro de Direito de Família - IBDFAM, de dezembro de 2016. Tal notícia informa sobre a realização de casamento inédito de pessoas com deficiência:

Em 17 de fevereiro, o Cartório de Registro Civil de Arthur Nogueira (SP) realizou o primeiro casamento de pessoa com deficiência intelectual no país. Depois de 19 anos de convivência e um filho de 17 anos, R.A.O.L, 44 e J.F.D, 53, finalmente se casaram $[\ldots]$

O titular responsável pelo cartório de Artur Nogueira, Fernando Marchesan Rodini Luiz, comentou sobre a importância da data e explicou que a pessoa interditada, assim como no caso de R. A. O. L, era considerada completamente incapaz, e para se casar dependia de uma ordem judicial. Mas, segundo ele, atualmente uma pessoa com deficiência intelectual não é mais considerada como totalmente incapaz, ou seja, qualquer pessoa nesta condição é considerada relativamente capaz, podendo gerir os seus atos da vida pessoal.

$[\ldots]$

A mudança implementada pelo texto faz parte do abandono do paradigma da exclusão, em busca da plena e efetiva inclusão da pessoa com deficiência no convívio social. Havendo vícios de consentimento ou manifestação de vontade, o casamento poderá ser anulado. A regra é a validade, sendo exceção a anulação do matrimônio, que deverá ser buscada judicialmente, momento em que serão produzidas as provas cabíveis. Segundo a Organização Mundial de Saúde, 10\% da população em países em desenvolvimento possuem algum tipo de deficiência, sendo que metade são pessoas com deficiência intelectual. Atualmente, no Brasil, existem 45 milhões de pessoas com algum tipo de deficiência. ${ }^{23}$

Observa-se que além de elevar o deficiente mental ao status de plenamente capaz, o Estatuto da Pessoa com Deficiência conserva a presença da curatela que, como estudado, se destina à proteção do maior absolutamente incapaz, sendo que pela primeira vez no ordenamento jurídico brasileiro apresentou-se a possibilidade de curatela, ainda que, sob nova perspectiva, para a pessoa absolutamente capaz.

Quanto às inovações da curatela, há de se destacar que, nos termos do art. 84, § 1ㅇ, do referido Estatuto, quando necessário, a pessoa com deficiência será submetida à curatela, conforme a lei, sendo que para o § 3 으, a curatela de pessoa com deficiência se constitui em medida protetiva extraordinária, proporcional às necessidades e às circunstancias de cada caso, e durará o menor tempo possível.

Na medida em que o Estatuto é expresso ao afirmar que a curatela é extraordinária e restrita aos atos de conteúdo patrimonial ou econômico, desaparece a figura da "interdição completa" e do "curador todo poderoso e com poderes indefinidos, gerais e ilimitados". Mas por óbvio, o procedimento de interdição (ou de curatela) continuará existindo, ainda que em uma nova perspectiva, limitada aos atos de conteúdo econômico ou patrimonial ${ }^{24}$.

\footnotetext{
${ }^{23}$ IBDFAM. Cartório paulista sai na frente e realiza casamento inédito de pessoa com deficiência depois da lei Brasileira de inclusão. Ano 2016. p. 01.

${ }^{24}$ GAGLIANO, Pablo Stolze. É o fim da interdição? 2016. p.02.
} 
O instituto da curatela, até então rígido, absoluto, e substitutivo da vontade da pessoa, ganha novos contornos, se apresentando agora como medida excepcional, delimitado às reais necessidades do interdito, os próprios poderes do curador são determinados e concedidos por tempo certo. Esse modelo passa a considerar gradativamente a exteriorização dos anseios da pessoa com deficiência mental, promovendo-lhe dignidade enquanto pessoa humana.

Em verdade, o que o Estatuto pretendeu foi, homenageando o princípio da dignidade da pessoa humana, fazer com que a pessoa com deficiência deixasse de ser "rotulada" como incapaz, para ser considerada - em uma perspectiva constitucional isonômica - dotada de plena capacidade legal, ainda que haja a necessidade de adoção de institutos assistenciais específicos, como a tomada de decisão apoiada e, extraordinariamente, a curatela, para a prática de atos na vida civil ${ }^{25}$.

A jurisprudência mais recente de alguns Tribunais, como do Tribunal de Justiça de Minas Gerais e do Acre, por exemplo, já se mostra compatível com as mudanças implementadas no paradigma da capacidade civil, considerando as disposições do Estatuto da Pessoa com Deficiência, conforme pode se verificar a seguir:

EMENTA: APELAÇÃO - AÇÃO DE INTERDIÇÃO - ESTATUTO DA PESSOA COM DEFICIÊNCIA / LEI № 13.146/2015 - DECLARAÇÃO DE INCAPACIDADE ABSOLUTA DESCABIMENTO - LIMITES DA CURATELA - SENTENÇA PARCIALMENTE REFORMADA Nos termos da Lei n. 13.146/2015, que, ao instituir a Lei Brasileira de Inclusão da Pessoa com Deficiência (Estatuto da Pessoa com Deficiência), revogou dispositivos do Código Civil, o exercício da curatela pressupõe alguns limites, não alcança o direito ao próprio corpo, à sexualidade, ao matrimônio, à privacidade, à educação, à saúde, ao trabalho e ao voto. Recurso parcialmente provido ${ }^{26}$.

EMENTE: DIREITO CIVIL. ESTATUTO DA PESSOA COM DEFICIÊNCIA. INTERDIÇÃO. CURATELA. MANIFESTAÇÃO DE VONTADE. IMPOSSIBILIDADE AFASTADA. INCAPACIDADE DESCARACTERIZADA. RECURSO DESPROVIDO. 1. O Código Civil passou por diversas alterações introduzidas pelo Estatuto das Pessoas Portadoras de Deficiência, notadamente quanto à capacidade dos deficientes, incluindo o instituto da curatela, tornada medida excepcional, limitadas às hipóteses do art. 1767, do Código Civil, que refogem ao caso concreto. 2. Apelação desprovida ${ }^{27}$.

Destaca-se que o Estatuto da Pessoa com deficiência incluiu no Código Civil, o art. 1.775-A, segundo o qual, na nomeação de curador para a pessoa com deficiência, o juiz poderá estabelecer curatela compartilhada a mais de uma pessoa. Relembra-se aqui dos

\footnotetext{
${ }^{25}$ GAGLIANO, Pablo Stolze. É o fim da interdição? 2016p. 03.

${ }^{26}$ BRASIL. Tribunal de Justiça de Minas Gerais. AC: 10000180663346001 MG, Relator: Kildare Carvalho, Data de Julgamento: 02/04/0019, Data de Publicação: 05/04/2019

27 BRASIL. Tribunal de Justiça do Acre. APL: 07000263220148010011 AC 0700026-32.2014.8.01.0011, Relator: Eva Evangelista, Data de Julgamento: 10/12/2018, Primeira Câmara Cível, Data de Publicação: 20/12/2018
} 
apontamentos de Dias, ${ }^{28}$ segundo os quais, tal medida reflete na garantia para o cidadão do pleno exercício de seus direitos fundamentais.

Diante das evidentes alterações na capacidade civil da pessoa com deficiência mental e da curatela destinada a estes, surge um natural questionamento, qual seja, o procedimento de interdição permanecerá vigente no sistema civil? Para responder ao questionamento parece razoável aceitar a posição de Gagliano ${ }^{29}$, o qual aduz que o procedimento de interdição continua a existir, ainda que sob uma nova perspectiva, limitado efetivamente aos atos de conteúdo econômico e patrimonial.

Sobre as interdições em curso, vale destacar que por alterar normas reguladoras de um aspecto fundamental (personalidade) o Estatuto porta aplicabilidade e eficácia imediatas, de sorte que mesmo para as interdições concretizadas e para as que se encontram em curso a pessoa passa a ser considerada absolutamente capaz.

Não se fala de uma suspensão total das interdições já efetivadas, mas sim de uma reconsideração quanto a sua abrangência, que deve considerar as restrições impostas pelo próprio Estatuto, ficando, por exemplo, o curador limitado à prática de atos meramente patrimoniais.

Rosenvald ${ }^{30}$ dispõe que a própria pessoa interessada será legitimada a pleitear o apoio, em substituição ao regime da curatela, na busca por um regime que recupere a capacidade fática, com menor limitação. Do que se extrai que nada obsta a solicitação da alteração da interdição pelo procedimento da tomada de decisão apoiada, uma vez que consiste em uma medida menos restritiva da autonomia existencial.

$\mathrm{O}$ art. 84, §2 do Estatuto da Pessoa com Deficiência e art. 1.783-A do Código Civil, indicam que a Tomada de Decisão Apoiada é uma medida facultada à pessoa com deficiência, segundo a qual, o sujeito elege ao menos duas pessoas idôneas com as quais mantenha vínculos e que gozem de sua confiança, para prestar-lhe apoio na tomada de decisão sobre atos da vida civil, fornecendo-lhes os elementos e informações necessários para que possa exercer sua capacidade.

A Lei inova, ao apresentar mais um instrumento ao sistema protetivo destinado às pessoas vulneráveis que até contava, fundamentalmente, com a Tutela para o menor de idade e a Curatela para o maior de idade incapaz. Ao que Rosenvald discorre:

Cuida-se de figura bem mais elástica do que a tutela e a curatela, pois estimula a capacidade de agir e a estabelecer a condição e qualidade das medidas de apoio e, se necessário, ser inscrita no Registro de Estado Civil e Capacidade de Pessoas. autodeterminação da pessoa beneficiária do apoio, sem que sofra o estigma social da curatela, medida nitidamente invasiva à liberdade da pessoa. Não se trata de um modelo limitador da capacidade de agir, mas de um remédio personalizado para as necessidades existenciais da pessoa, no qual as medidas de cunho patrimonial

\footnotetext{
${ }^{28}$ DIAS, Maria Berenice. Manual de direito das famílias. 10. ed. rev., atual. e ampl. São Paulo: Editora Revista dos Tribunais, 2015.

${ }^{29}$ GAGLIANO, Pablo Stolze. É o fim da interdição? 2016.

30 ROSENVALD, Nelson. A Tomada De Decisão Apoiada - Primeiras linhas sobre um novo modelo jurídico promocional da pessoa com deficiência. 2015.
} 
surgem em caráter acessório, prevalecendo o cuidado assistencial e vital ao ser humano ${ }^{31}$.

Diferente da curatela, que tende a restringir a capacidade de agir do sujeito, primordialmente quanto ao seu patrimônio, a Tomada de Decisão Apoiada considera as necessidades existenciais das pessoas com deficiência mental, não se restringindo à administração dos bens desta, mas se revelando, conforme citado, em um remédio personalizado destinado ao próprio cuidado humano.

Outra diferença que se destaca com relação à curatela é que a indicação dos prestadores de apoio parte de uma indicação da própria pessoa com deficiência, a qual elegerá seus auxiliares de acordo com os vínculos e com a confiança existentes entre eles e o apoiado. Não parte, portanto, de imposição estatal como acontece com a curatela.

Sobre a possibilidade de escolha dos auxiliares, Requião ${ }^{32}$ registra que se privilegia, assim, o espaço de escolha do portador de transtorno mental, que pode constituir em torno de si uma rede de sujeitos baseada na confiança que neles têm, para lhes auxiliar nos atos da vida civil.

Para formulação do pedido da Tomada de Decisão Apoiada é necessário que a pessoa com deficiência e seus apoiadores apresentem, em juízo, termo que informe o tipo de apoio solicitado, bem como os compromissos dos apoiadores, devendo constar ainda o prazo de vigência do termo. 0 art. 1.783-A, § 9o, do Código Civil, informa ainda que a qualquer tempo pode solicitar o término do acordo firmado no processo de Tomada de Decisão Apoiada.

Pode ocorrer, entretanto, de o juiz ou o Ministério Público constatar que, devido a agravamentos do estado psicológico do sujeito, a Tomada de Tecisão Apoiada já não surte o efeito desejado, caso em que a medida de apoio poderá cessar com a decretação da curatela e, consequente, substituição dos apoiadores designados por curador.

Rosenvald $^{33}$ (2015) informa que a intervenção na autonomia se dará, nesse novo sistema, em uma gradação tripartite, no primeiro caso, as pessoas com deficiência terão capacidade plena, no segundo, as pessoas com deficiência se servirão da Tomada de Decisão Apoiada a fim de exercer a sua capacidade em igualdade de condição que os demais e, finalmente, a pessoa qualificada para a curatela em razão de impossibilidade de autogoverno serão interditadas.

\section{CRÍTICAS AO NOVO MODELO DE INCAPACIDADES ADOTADO PELA LEI № 13.146/2015}

Apesar de todos os avanços já elencados, é evidente que uma alteração tão significativa no sistema de incapacidades civil resulta, em um primeiro momento, em

\footnotetext{
31 ROSENVALD, Nelson. A Tomada De Decisão Apoiada - Primeiras linhas sobre um novo modelo jurídico promocional da pessoa com deficiência. 2015. p.02.

${ }^{32}$ REQUIÃO, Maurício. Estatuto da Pessoa com Deficiência: Incapacidades e Interdição. Juspodivm: Bahia. 2016.

33 ROSENVALD, Nelson. A Tomada De Decisão Apoiada - Primeiras linhas sobre um novo modelo jurídico promocional da pessoa com deficiência. 2015.
} 
incertezas quanto a sua efetiva aplicação e quanto à possibilidade de cumprimento dos objetivos almejados pela nova legislação.

Há, ainda, que se considerar a necessidade de se operar uma desconstrução ideológica por parte daqueles que por muito tempo acreditaram fielmente que a melhor forma de proteger os interesses da pessoa com deficiência é a interdição. Nesse sentido, e considerando o próprio método aplicado no presente trabalho é necessário abordar, mesmo que brevemente, as principais críticas observadas sobre o Estatuto da Pessoa com Deficiência.

Simão ${ }^{34}$, assim como outros autores desfavoráveis ao Estatuto, entende que, quando a Lei $n$ ㅇ 13.146/2015 passa a considerar as pessoas com deficiência mental absolutamente capazes, a prescrição e a decadência podem correr contra estas, uma vez que não foram alterados os artigos 198, I, e 208, do Código Civil, o que seria extremamente prejudicial para elas.

Ainda, segundo o raciocínio do autor, a quitação dada pela pessoa com deficiência será considerada eficaz e válida, conforme art. 310 do Código Civil. Haverá também a seu entender a necessidade de o deficiente exprimir sua vontade para o recebimento de doações, o que, atualmente, era dispensado nos termos do art. 543 do Código Civil, o que seria prejudicial àqueles impossibilitados de manifestar a sua vontade.

Outro ponto destacado, reside na reponsabilidade por danos, haja vista que, ao seu entendimento, a concessão da capacidade absoluta resulta que a pessoa com deficiência "passará a responder com seus próprios bens pelos danos que causar a terceiros, afastandose a responsabilidade subsidiária criada atualmente pelo artigo 928 do CC."35

Mesmo respeitando as considerações trazidas pelo autor, há de se lembrar que a Convenção Sobre os Direitos das Pessoas com Deficiência, a qual originou a edição do Estatuto da Pessoa com Deficiência, foi recepcionada no ordenamento jurídico brasileiro como norma formalmente constitucional, estando, portanto, em um nível hierárquico superior ao próprio Código Civil, de sorte que o mesmo deve ser interpretado, quando de sua aplicação, de acordo com os preceitos ali adotados.

Leciona Santos ${ }^{36}$ que os dispositivos da Lei no $13.146 / 2015$ devem ser cotejados e interpretados, inevitavelmente, em conformidade com as normas e princípios constantes na Convenção das Pessoas com Deficiência, o que, a rigor, corresponde ao raciocínio de que as leis ordinárias devem ser interpretadas de acordo com a Constituição.

É evidente que o ordenamento não deixou de considerar a pessoa com deficiência como um sujeito vulnerável, tanto o é que os instrumentos protetivos foram repensados em prol dessa dita vulnerabilidade, não cabendo afirmar, de pronto, que o Estatuto surge como um regramento essencialmente prejudicial aos sujeitos por ele tutelados. Nesse sentido:

O que não se pode, em absoluto, é permitir que normas jurídicas que vieram a lume para proteger o direito das pessoas com deficiência sirvam para agravar a sua

\footnotetext{
${ }^{34}$ SIMÃO, José Fernando. Estatuto da Pessoa com Deficiência causa perplexidade. 2015.

${ }^{35}$ SIMÃO, José Fernando. Estatuto da Pessoa com Deficiência causa perplexidade. 2015. p.05.

${ }^{36}$ SANTOS, Bruno Henrique Silva. Prescrição e decadência contra as pessoas com deficiência após a promulgação da Lei n. 13.146/15: uma análise constitucional. 2016.
} 
situação, deixando-as em um estado (ainda maior) de vulnerabilidade que não existia anteriormente.

$[\ldots]$

O que a Convenção pretende deixar claro, com isso, é que as suas disposições jamais poderão servir para a redução da esfera de proteção das pessoas com deficiência quando as normas internas do Estado Parte sejam mais favoráveis. ${ }^{37}$

O pensamento do autor parece bem acertado para os casos mencionados, ainda que seu estudo se debruce apenas sobre a prescrição, uma vez que o art. 4ㅇ, 4, da Convenção deixa evidente que nenhum dispositivo dela afetará disposições mais propícias à realização dos direitos das pessoas com deficiência, as quais possam estar contidas na legislação do Estado Parte ou no direito internacional em vigor para esse Estado.

É notório que, em razão da aparente incompatibilidade entre alguns dispositivos do Código Civil e da Convenção sobre os Direitos da Pessoa com Deficiência, cabe a interpretação do Código de acordo com a Constituição, de forma que não sejam reduzidos direitos anteriormente concedidos aos vulneráveis, o que não representa tratamento diferenciado com relação a estes, posto que o art. 5o, 4 da referida Convenção afirma que as medidas específicas que forem necessárias para acelerar ou alcançar a efetiva igualdade das pessoas com deficiência não serão consideradas discriminatórias.

$\mathrm{Na}$ oportunidade, relembra-se que a igualdade para as minorias não se esgota no campo meramente formal, seguindo a fórmula de que todos são iguais sem distinção, carecendo de consideração o aspecto material para que o ordenamento jurídico possa dar efetividade na promoção da igualdade.

\section{- CONCLUSÃO}

Cabe relembrar que o estudo tinha como hipótese que o reconhecimento da capacidade civil daqueles que possuem deficiência mental tendia a concedê-los maior dignidade da pessoa humana. De sorte que os estudos realizados demonstram que:

a) Os instrumentos protetivos antes postos, eram considerados rígidos, e visavam substituir a vontade da pessoa então considerada incapaz, mostrando-se extremamente invasivos e, na prática, não se restringiam apenas à esfera patrimonial da pessoa, tocando em verdade na sua autonomia existencial resultando em violação na própria personalidade do sujeito, motivos pelos quais já se indicava a necessidade de revisão da teoria das incapacidades utilizada.

b) O Estatuto da Pessoa com Deficiência trouxe uma reorganização nos padrões de capacidade civil. A Curatela bem como a Tomada de Decisão Apoiada tais quais apresentadas na legislação em vigor tendem a contribuir gradativamente para a valorização de um grupo antes desvalorizado na esfera civil.

\footnotetext{
${ }^{37}$ SANTOS, Bruno Henrique Silva. Prescrição e decadência contra as pessoas com deficiência após a promulgação da Lei n. 13.146/15: uma análise constitucional. 2016. p. 05.
} 
c) Verificam-se os avanços registrados no decorrer da legislação civil, que, em um primeiro momento, considerava o "louco de todo gênero" absolutamente incapaz, o qual não podia sequer ter um casamento considerado válido para o estado atual, que o valoriza efetivamente enquanto ser humano, considerando-o capaz de exercer seus direitos em igualdade de condições e possibilitando a este gerência mais amplamente da sua própria vida.

d) A Lei no 13.146/2015 não deixou de reconhecer que a pessoa com deficiência mental é vulnerável, e por consequência merecedora de maior atenção, mas cuidou em conceder maior liberdade para a sua consideração como pessoa, o que se mostra absolutamente compatível com o fundamento constitucional da dignidade da pessoa humana.

Após a apresentação de tais argumentos, a pesquisa concluiu pela confirmação da hipótese levantada, entretanto, cabe destacar que a alteração legislativa, por si só, não garante a implementação de todos os direitos idealizados na Lei no $13.146 / 2015$, sendo necessária a modificação cultural dos próprios operadores do direito, que devem iniciar uma desconstrução ideológica, que, pode acabar se estendendo por longos anos.

A retirada da condição de incapaz não garante o pleno exercício de direitos da pessoa com deficiência mental, devendo o Estado honrar os compromissos assumidos internacionalmente enquanto signatário da Convenção Sobre os Direitos da Pessoa com Deficiência promovendo as políticas públicas necessárias à efetivação do referido dispositivo.

As dificuldades, quanto à aplicação do novo sistema de capacidades, poderão ser superadas no momento em que o respeito pela existência do outro e por seus direitos for reconhecido nacionalmente, o que se processará, por meio da educação e informação de tais direitos, de forma ampla e contínua.

\section{REFERÊNCIAS}

ABREU, Célia Barbosa; VAL, Eduardo Manuel. A flexibilização da curatela para o psicopata: uma interpretação constitucional pelo Superior Tribunal de Justiça. Revista da AJURIS - v. 41 - n. 134 - Rio Grande do Sul: Ajuris, 2014. Disponível em:

<http://www.ajuris.org.br/OJS2/index.php/REVAJURIS/article/view/197>. Acesso em: 10 abr. 2019.

DECLARAÇÃO UNIVERSAL DOS DIREITOS HUMANOS. Assembleia Geral das Nações Unidas em Paris. 10 dez. 1948. Disponível em:

<https://www.ohchr.org/EN/UDHR/Pages/Language.aspx?LangID=por>. Acesso em: 26 jun. 2016.

DIAS, Maria Berenice. Manual de direito das famílias. 10. ed. rev., atual. e ampl. São Paulo: Editora Revista dos Tribunais, 2015.

GAGLIANO, Pablo Stolze. É o fim da interdição? Disponível em:

<https://jus.com.br/artigos/46409/e-o-fim-da-interdicao>. 2016. Acesso em: 04 abr. 2016.

GAGLIANO, Pablo Stolze; PAMPLONA FILHO, Rodolfo. Manual de Direito Civil. São Paulo: Saraiva Educação, 2018

GONÇALVES, Carlos Roberto. Direito de família. 16. ed. - São Paulo: Saraiva, 2012. - (Coleção sinopses jurídicas; v. 2) 
IBDFAM. Cartório paulista sai na frente e realiza casamento inédito de pessoa com deficiência depois da lei Brasileira de inclusão. Ano 2016. Disponível em:

<http://ibdfam.org.br/noticias/5919/Cart\%C3\%B3rio+paulista+sai+na+frente+e+realiza+o+p rimeiro+casamento+de+pessoa+com+defici\%C3\%AAncia,+depois+da+Lei+Brasileira+de+Incl us\%C3\%A3o>. Acesso em: 16 fev. 2017.

PIOVESAN, Flávia. in Novos Comentários à Convenção sobre os Direitos das Pessoas com Deficiência. Secretaria de Direitos Humanos da Presidência da República (SDH/PR)/Secretaria Nacional de Promoção dos Direitos da Pessoa com Deficiência (SNPD): Brasília, 2014. Disponível em:

$<$ http://www.pessoacomdeficiencia.gov.br/app/sites/default/files/publicacoes/convencaosdpcd-novos-comentarios.pdf>. Acesso em: 15 out. 2016.

PORTUGAL. Ordenações Afonsinas. Coimbra: na imprensa de Portugal, 1792. Disponível em: <http://bd.camara.leg.br/bd/handle/bdcamara/20280>. Acesso em: 18 fev. 2017.

PORTUGAL. Ordenações Filipinas. 14a edição segundo a primeira de 1603 e a 9a de Coimbra de 1824, por Candido Mendes de Almeida. Rio de Janeiro: Typ. do Instituto Philomathico, 1870. Disponível em: <http://www2.senado.leg.br/bdsf/handle/id/242733>. Acesso em: 18 fev. 2017.

PORTUGAL. Ordenações Manuelinas. Coimbra: na real imprensa da Universidade, 1797. Disponível em: <http://bd.camara.gov.br/bd/handle/bdcamara/17841>. Acesso em: 18 fev. 2017.

REQUIÃO, Maurício. Estatuto da Pessoa com Deficiência: Incapacidades e Interdição. Juspodivm: Bahia. 2016

ROSENVALD, Nelson. A Tomada De Decisão Apoiada - Primeiras linhas sobre um novo modelo jurídico promocional da pessoa com deficiência. 2015. Disponível em:

<http://www.nelsonrosenvald.info/artigos-jurdicos>. Acesso em: 21 out. 2016.

SANTOS, Bruno Henrique Silva. Prescrição e decadência contra as pessoas com deficiência após a promulgação da Lei n. 13.146/15: uma análise constitucional. Disponível em: <https://jus.com.br/1403953-bruno-henrique-silva-santos/publicacoes>. 2016. Acesso em: 23 out. 2016.

SIMÃO, José Fernando. Estatuto da Pessoa com Deficiência causa perplexidade. Disponível em: <http://www.conjur.com.br/2015-ago-06/jose-simao-estatuto-pessoa-deficienciacausa-perplexidade>. 2015. Acesso em: 11 abr. 2016. 